\title{
THE PROBLEM OF CONSCIOUSNESS.
}

\section{COMMENTS ON PROFESSOR MINOT'S DUALISM.}

$\Lambda^{\mathrm{T}}$ the last meeting of the American Association for the AdSedgwick Minot of Harvard University, delivered the usual presidential address before a large and select audience in Carnegie Hall, Pittsburgh, $\mathrm{Pa}$., and his subject was "The Problem of Consciousness in Its Biological Aspects." The speaker was a whitebearded gentleman of dignified appearance with a somewhat dreamy eye. He had an engaging presence, and a distinct consciousness of his authority.

The speech was characterised by a vehement attack on Monism. Professor Minot said :

"Monism is not a strong system of philosophy, for it is not so much the product of deep and original thinking as the result of a contemporary tendency. It is not the inevitable end of a logical process, because it omits consciousness, but rather an incidental result of an intellectual impulse. Its very popularity betokens its lack of profundity, and its delight in simple formulæ is characteristic of that mediocrity of thought which has much more ambition than real power and accepts simplicity of formularisation as equivalent to evidence. It would seem stronger, too, if it were less defended as a faith. Strong partisans make feeble philosophers.

"Monism itself is postulated chiefly upon the two greatest discoveries of the nineteenth century - the law of the conservation of energy, and the law of the evolution of species. Both laws establish a greater unity in the phenomena of the universe than mankind had previously been able to accept. In the physical world, instead of many forces, we now recognise only one force, which assumes various forms of energy; and in the living world we recognise one life, which manifests itself in many types of forms. With these two unities in mind, what could be nearer than the thought that the unity goes still deeper, and that the phenomena 
of the inanimate or physical, and of the living world are fundamentally identical ? The progress of physiological science has greatly increased the impetus towards the adoption of this thought as the cardinal dogma of the new faith, because the work of physiologists has been so devoted to the physical and chemical phenomena of life, that the conviction is widespread that all vital phenomena are capable of a physical explanation."

Now I do not know any biologist of standing who either is not a monist, or at least does not carry on his investigations with methods along monistic lines of thought. In fact, most of our naturalists and even philologists are monists; and there are almost as many kinds of monism as there are original thinkers: the philologist F. Max Müller's monism is radically different from Haeckel's, and Professor Wundt's is different from either.

In rejecting the monistic conception of consciousness, Professor Minot should at least have indicated whose monism he combated, and he would have been wise to explain and refute either Wundt or Hering or some other monist of unequivocal standing.

I would find no fault with Professor Minot for cherishing and professing dualistic views, but it seems unwarranted and improper to use for his tirades the occasion of a presidential address, which ought to be a representative condensation of the present state of his science. But the most objectionable feature of his address is its lack of positive information. And while Professor Minot is very decided in his censure, his own theories are vague and an explanation of the problem of consciousness is nowhere forthcoming. On account of its barrenness, the lecture does not deserve mention of any kind, and would have been ignored had it not been for the prominence that naturally attaches to the presidential address of a great association with scientific pretensions, the rank of the lecturer as professor in one of our most celebrated universities, and its prominent appearance in Science and in the Popular Science Monthly.

Professor Minot promised to discuss the problem of consciousness in its biological aspect, but he does not even allude to one single biological fact that would help us to understand better the functions of consciousness. Biology is only referred to in general terms and the statement is made that: 
"The biologist must necessarily become more and more the supreme arbiter of all science and philosophy, for human knowledge in itself is a biological function, etc."

I should like to see Professor Minot use his biology as a criterion for the solution of an algebraic equation, or a question of historical evidence, or for the interpretation of a $\dot{a} \pi a \xi \lambda \epsilon \gamma o ́ \mu \epsilon \nu \nu$ in a cuneiform inscription, or apply it to the theory concerning the motions of the stars in the milky way, or to the speculations as to the origin of motion or the ultimate constitution of the chemical elements. I do not think that I have ever underrated the importance of biology, but if Professor Minot be right his colleagues had better abandon the study of chemistry, philosophy, philology, history, mathematics, etc., and apply themselves to biology, though I fear that on these lines the science of the future would become somewhat one-sided.

But let us hear what Professor Minot has to say on consciousness. He sets out with the following considerations:

"The time is not yet for giving a satisfactory definition of consciousness, and we must fain content ourselves with the decision of the metaphysician, who postulates consciousness as an ultimate datum or concept of thought, making the brief dictum cogito, ergo sum the pivot about which his system revolves. I have endeavored vainly to discover by reading and by questioning those philosophers and psychologists whom I know, some deeper analysis of consciousness, if possible, resolving it into something more ultimate.

"Opinions concerning consciousness are many and often so diverse as to be mutually exclusive, but they may be divided into two principal classes. The first class includes all those views which make of consciousness a real phenomenon; the second, those views which interpret it as an epiphenomenon. We are, I think practically all, agreed that the fundamental question is : Does or does not consciousness affect directly the course of events?-or, stated in other words, is consciousness a true cause? In short, we encounter at the outset the problem of freewill ; of which more later."

Almost every sentence contains a wrong contrast and betrays a lack of logical clearness. It is a fair sample of the Professor's mode of thought; but we cannot lose ourselves in details, and so forego analysing it.

Monism is made responsible for the theory that consciousness is an epiphenomenon : 
"The opinion that consciousness is an epiphenomenon has gained renewed prominence in recent times, for it is, so to speak, a collateral result of that great movement of European thought which has culminated in the development of the doctrine of monism."

And what is an epiphenomenon? Here is Professor Minot's explanation :

"It is essential to have a clear notion of what is meant by an epiphenomenon. Etymologically the word indicates something which is superimposed upon the actual phenomenon. It designates an accompanying incident of a process which is assumed to have no causal relation to the further development of the process. In practice it is used chiefly in regard to the relation of the mind or consciousness to the body, and is commonly employed by those philosophers who believe that consciousness has no causal relation to any subsequent physiological process."

In using the term epiphenomenon Professor Minot obviously refers to the Fechner-Weber theory of parallelism between consciousness and nervous activity, but his résumé is so misleading as to be almost beyond recognition. And what is his own result? First he states:

"The most striking distinction of the processes in living bodies, as cumpared with those in inanimate bodies, is that the living processes have an object, -they are teleological."

And he concludes:

"In order to determine the teleological value of consciousness, we must endeavor to make clear to ourselves what the essential function is which it performs. As I have found no description or statement of that function which satisfied me, I have ventured, perbaps rashly, to draw up the following new description:

"The function of consciousness is to dislocate in time the reactions from sensations."

This determination of the function of consciousness is as stilted as it is futile. It appears that Professor Minot confuses consciousness with memory and describes how former sense-impressions are awakened by similar present sensations. Here is his more explicit explanation :

"Consciousness may evoke a reaction from a remembered sensation and combine it with sensations received at other times. In other words, consciousness bas a selective power, manifest both in choosing from sensations received at the same time and in combining sensations received at different times. It can make syn- 
chronous impressions dyschronous in their effects, and dyschronous impressions syncbronous. But this somewhat formidable sentence merely paraphrases our original description: The function of consciousness is to dislocate in time the reactions from sensations."

The process to which Professor Minot refers is not at all exclusively a function of consciousness. Every sense-impression leaves a trace of a definite form. When a new sense-impression of the same kind is made, it travels on the path prepared by the former sense-impression and reawakens its memory trace. This process is the common type of sense-activity which becomes possible on account of the retention of old traces, - a condition which is called memory. It may take place consciously or unconsciously, but there is nowhere in this process "a selecting power" of consciousness; no choosing takes place, and the dislocation in time which changes synchronous into dyschronous impressions and vice versa is (so far as the choosing is concerned) a mechanical combination of the same or similar features of new and old senseimpressions. Sensations travel in the paths prepared for them by analogous prior sensations, as in the type-distributing machine the several letters travel to their respective places.

It betrays a lack of the most elementary knowledge of consciousness that the description of consciousness as a dislocator is the sum-total of Professor Minot's wisdom. He harps on the same string again and again, insisting upon the importance of the idea. He declares :

"This disarrangement and constant rearrangement of the sensations, or impressions from sensations, which we gather, so that their connections in time are altered seems to me the most fundamental and essential characteristic of consciousness which we know."

He repeats himself, saying :

"The characteristic we are considering is certainly important, and so far as the available evidence goes it belongs exclusively to consciousness."

And further down he goes into details:

"Thus, for example, the child sees an object, and its reaction is to take bold of the object, which is hot and hurts the child. Later the child sees the object again and its natural reaction is to take hold of it again, but the child now reacts 
differently because its consciousness utilises the earlier as well as the present sensation: the previous sensation is dislocated in time and fused with the present sensation and a new reaction follows."

That which is true in all this is trivial, but whether true or not, it sheds no light on the biological function of consciousness. At the same time Professor Minot's style is vitiated by expressions which imply that consciousness is something apart from other mental functions, for consciousness is represented as selecting, as choosing, as utilising, etc. Does Professor Minot really think that there is a consciousness in itself? It seems incredible, but it may be that when he denounces monism for denying the existence of consciousness, he means to say that the monistic view knows only mental states that are conscious, but does not recognise the independent existence of consciousness as an entity in itself. Professor Minot does not expressly state it, so I leave the question undecided.

Professor Minot further makes a few incidental remarks from which we quote the following sentences:

"The evidence is overwhelming that animals bave a consciousness homologous with the human consciousness....

"Conscious actions are primary ; reflex and instinctive actions secondary....

"Human evolution is the continuation of animal evolution, and in both the dominant factor has been the increase of the resources available for consciousness....

"Consciousness stands in immediate causal relations with physiological processes."

Finally Professor Minot winds up with the following consideration :

"Probably no question is so profoundly interesting to all mankind as the old question, what is the relation of the mind to the body? It is a question which has been stated in many forms and from many points of view, but the essential object of the question is always the same, to ask whether consciousness is a function of living matter, or something discrete and not physical or material."

And here is the Professor's answer:

"Consciousness has the power to change the form of energy, and is neither a form of energy nor a state of protoplasm."

This is practically all he has to say on "consciousness in its biological aspects." 
Professor Minot's use of the terms "power" and "energy" is very loose and therefore the last quotation (which declares that consciousness "has power" although it is not "energy") must not be taken too seriously and certainly not literally.

Now I would like to discuss the problem of consciousness as I think it ought to be treated, but having tired my readers with an exposition of Professor Minot's views I feel that I had better limit myself to a few comments on his two bugbears-Monism and Epiphenomenon.

Monism according to Professor Minot must be a very mischievous idea and it seems a great misfortune that it has found much favor, not with the masses (for monism is by no means a popular theory), but with naturalists, the leaders in the realm of science.

Let us see what monism ${ }^{1}$ has come to stand for.

Monism means the doctrine of unity, and there are different kinds of monism according to the standpoint chosen by different thinkers. There is a spiritual monism, there is a dynamic monism, there is a materialistic monism. Further there are combinations of the three and the agnostic monism. Büchner's monism recognises matter and force, Fechner's the parallelism of soul and body, etc. All these monisms seek the unity of the world in the assumption that there is one substance only. My own monism is different, as I seek the unity of existence not in the material of which it consists but in its mode of existence. I look upon all reality as one great system and upon all our concepts as abstract ideas, which the more general they are will prove to be more void of content. All of them have ultimately been derived from experience. Knowledge is a description of things or conditions; and if the description is appropriate so as to allow us to predict or even predetermine the course of events (if thought and thing tally), we call our description true. I cannot enter into further details, but the applications of this fundamental principle are manifold and important.

${ }^{1}$ The word was coined by Wolf, but it came into general use only in the latter half of the nineteenth century. 
It implies that there are no things-in-themselves. There is no matter-in-itself, no energy-in-itself, no soul-in-itself, no consciousness-in-itself, no memory-in-itself. Consciousness (like whiteness) is a generalisation which is used to denote the characteristic quality of those various conditions that are conscious. Memory is not a faculty, but a general characteristic of mental life. It is an abstract term comprehending in one word the peculiarity due to a preservation of the traces which all physiological activities leave. Accordingly monism (as I understand it) means that all truths, if rightly understood, will form one great system of truths. There may be a contrast, but there will never be a contradiction. Dualism can have two contradictory truths. As the schoolmen said, a statement may be true in philosophy and untrue in theology, and vice versa. Monism does not reject the duality of contrasts, but endeavors to reconcile them in a higher unity. There can never be two contradictory truths, and whenever two truths seem to be contradictory, we have a problem.

Monism accordingly is not so much a ready doctrine as a plan of work, a method; and I need scarcely add that this method has proved very fruitful in the history of science. It has stimulated all the natural sciences, especially physiology, psychology, and also Professor Minot's science, biology, but the progress of the age seems to be barred out from his laboratory. It did not enter there and the professor has profited little by it.

In conclusion $I$ have to add a few comments on the term epiphenomenon, which has been adopted by a few modern psychologists to denote consciousness as a phenomenon superadded to physiological brain-processes. The original use of the word is limited to medical nomenclature and means simply "a secondary function"; but when the non-mechanical and non-material quality of consciousness became fully understood, some physiological psychologists introduced the term to emphasise the fact that consciousness is a function radically different from brain-activity and thus they spoke of it as superadded to cerebral motions, being a phenomenon sui generis, which according to conditions not yet understood appears and disappears, but is itself not a motion, not a 
mechanical process, not a material substance, and in order to give it a name, they called it an epiphenomenon in contrast to the phenomena of the objective world which are modes of matter in motion.

I myself have never used the term "epiphenomenon," and am therefore free to condemn it without compromising myself. I never liked the term because it seems to indicate that consciousness is incidental and its presence or absence would be of no account. This of course is not so, although there are psychologists who have taken that stand. I believe it was Huxley who went so far as to compare consciousness to the sparks thrown out by a steam-engine which give a little light but have no power to alter the movements of the engine; may be it was some other naturalist. For our present purpose, it matters not who it was, so long as it was not a confessed monist, and Huxley is an agnostic; he takes a position. which though practically opposed to dualism would neither deny nor affirm its principles or main tenets. The idea that consciousness is an indifferent phenomenon has been emphatically rejected by Hering, Wundt, Ribot, and also by myself. But while the paramount significance of consciousness must be acknowledged, the statement remains true that consciousness is not a brain-motion but a superadded phenomenon; it is an accompaniment of certain physiological processes, being the subjective phase of certain objective phenomena. If the term epiphenomenon is used in this sense, it is quite proper to speak of consciousness as an epiphenomenon. We need some term for it, and epiphenomenon (if it be only commonly accepted) will do as well as any other word. Prof. C. Lloyd Morgan, in order to distinguish consciousness from motion or kinesis, calls the realm of the subjective "metakinesis"; and Professor Minot, in declaring that "consciousness is not a form of energy," sides unknowingly with that large party of monists so vigorously condemned by him who call it an epiphenomenon, or metakinesis, i. e., a function not belonging to that set of phenomena which are modes of matter in motion.

If consciousness is not a motion, it is obvious that it cannot move. Accordingly consciousness (if it is not a form of energy) 
can neither push nor pull, and this is the import of the simile in which it is compared to the sparks of the steam-engine. The simile is inappropriate, as might be expected of a simile, for says the Roman proverb omne simile clauticat. Even Professor Minot is sometimes extravagant in his comparisons. He says for instance:

"All science belongs in the same category as the teleological efforts of a jelly fish or a lobster. It is work done at the command of consciousness to satisfy the needs of existence."

I am far from denying what Professor Minot means, but his humility seems to me exaggerated when he classifies his professional work in the same category with "the efforts of a jelly-fish or a lobster."

If we take the simile of the spark-throwing engine cum grano salis, it remains perfectly true; but I should prefer to compare consciousness to the light in an engine-room which has no visible effect upon the mechanical motions either of the engine or of the muscles of the engineer; but merely reflects the picture of the surroundings upon the retina of the engineer's eye, thus enabling him to see the wheels and levers and assisting him in directing the movements of the machinery. Even this simile is inaccurate, as (in the widest sense of the term) the ether waves of light are also mechanical; but, if not wilfully misunderstood, it will help to explain the rôle of consciousness in its paramount importance and at the same time its utter want of mechanical power. Thus we recognise the truth of what Professor Minot tries to express in his paradox that consciousness "has the power to change the form of energy, but it is not a form of energy itself."

Consciousness is an abstract term, like whiteness or transparency, or any other generalisation. The quality of consciousness that is attached to a nervous state does not add an iota of mechanical power to it, but it modifies its character so as not to be an irrelevant factor in the economy of the mind. Consciousness, though not itself a motion, is the most significant feature of existence. And here is the point where I would shake hands with Professor Minot and forgive him his superficiality and lack of scientific insight. He is groping after an important truth, but he is 
groping in the dark. His heart is probably on the right track, but the mechanism of his logical operations got somewhat out of gear and threw him off the track, and not knowing where to lay the blame of his confusion, he rails at the doctrine of monism which he has proved unable to comprehend.

Professor Minot thinks that monism "involves the elimination of the two concepts God and consciousness," and he adds that "monists sometimes use these words, but it is mere jugglery, for they deny the concept for which the words actually stand." May the God of monism forgive Professor Minot for his blasphemous utterances. May He who is the underlying norm of the cosmic order, the omnipresent principle of the so-called laws of nature, the eternal standard of truth, and the ultimate condition of all correct thinking, - - He who is the most real reality of all actual as well as potential existence, and not mere jugglery, - may $\mathrm{He}$, the God of Science, take compassion upon the confused condition of Professor Minot's brain. May he illumine his mind. May $\mathrm{He}$ who is One and co-eternal with the Logos forgive him his lack of logic and other failings and lead him gently on the path of science to a deeper and better comprehension of the truth. Amen.

EDIToR. 